\title{
Selection of Renewable Energy Based on Life Cycle Assessment and Multi-Criteria Decision Making
}

\author{
Wen-Fang Wu', Yao Hsu ${ }^{2 *}$, Ya-Ju Chang ${ }^{3,4}$, Ying-Chu Chen ${ }^{5}$ \\ ${ }^{1}$ Department of Mechanical Engineering and Graduate Institute of Industrial Engineering, National Taiwan \\ University, Taiwan \\ ${ }^{2}$ Department of Business and Entrepreneurial Management, Kainan University, Taiwan \\ ${ }^{3}$ Graduate Institute of Industrial Engineering, National Taiwan University, Taiwan \\ ${ }^{4}$ Department of Environmental Technology, Technische Universität Berlin, Berlin, Germany \\ ${ }^{5}$ Institute of Natural Resource Management, National Taipei University, Taiwan \\ Email: "yhsu@mail.knu.edu.tw
}

Received 26 December 2015; accepted 29 February 2016; published 3 March 2016

Copyright (C) 2016 by authors and Scientific Research Publishing Inc.

This work is licensed under the Creative Commons Attribution International License (CC BY).

http://creativecommons.org/licenses/by/4.0/

cc) (i)

Open Access

\section{Abstract}

The development of renewable energy has become an important issue nowadays owing to the growing concerns about global warming and shortage of fossil fuels. The present study proposes an approach that integrates life cycle assessment (LCA), 3E (Energy-Economics-Environment) indicators and multi-criteria analysis (MCA) to evaluate environmental impacts and find the best choice or better choices among various renewable energy development plans. Several alternatives of wind turbines and photovoltaic (PV) systems are considered in the case study since they are found to be more feasible in Taiwan in a preliminary study. By using the proposed approach, the result indicates that the major environmental impacts arising from the development of wind turbines and PV systems in Taiwan are the generation of respiratory in-organics and minerals as well as the consumption of fossil fuels. Based on experts' opinions, the outcome of multi-criteria analysis suggests that wind turbines have more advantages than PV systems in Taiwan. In particular, among the studied systems, a $2500-\mathrm{kW}$ offshore wind turbine system has the greatest integrated performance, and a $4500-\mathrm{kW}$ onshore wind turbine system comes in second.

\section{Keywords}

Renewable Energy, Life Cycle Assessment, Multi-Criteria Decision Making

\footnotetext{
${ }^{*}$ Corresponding author.
}

How to cite this paper: Wu, W.-F., Hsu, Y., Chang, Y.-J. and Chen, Y.-C. (2016) Selection of Renewable Energy Based on Life Cycle Assessment and Multi-Criteria Decision Making. Open Journal of Energy Efficiency, 5, 1-11. 


\section{Introduction}

Owing to the growing environmental concern over the global warming caused by greenhouse effect, the development of renewable energy to reduce undesired gas emissions has become an important issue worldwide. Meanwhile, in order to understand the environmental impacts of power generation as well as industrial activities, numerous researches and several advanced tools have been proposed during the last decade. In particular, life cycle assessment (LCA), performance indicators and multi-criteria analysis (MCA) have been used for quite a few analyses. LCA, called cradle-to-grave approach, is a systematic approach used to estimate the performance as well as its associated environmental impacts of a product or service over its lifetime [1]. It includes phases of design, manufacturing, transportation, operation, maintenance and disposal. Martinez et al. applied LCA to analyze all phases of wind farm with regarding key components, and suggested it to improve the manufacturing processes to reduce environmental burdens [2]. To improve the evaluation capability and to set up a unified standard, researchers have proposed various performance indicators to assess the development of different types of renewable energy [3] and their corresponding feasibilities. However, during the development of an energy plan, issues of energy, economics and environmental factors may create conflicts with one another. MCA can resolve this dilemma and provide support for the selection of an appropriate energy development plan among multiple alternatives [4]. By combining cost and revenue assessment, Cavallaro used MCA process to estimate the economical performances of different concentrated solar thermal technologies [5].

A few researchers have combined LCA, environmental performance indicators and MCA together as an integrated tool. Among them, Hermann et al. [6] had proposed a "COMPLIMENT" method that combined environmental performance indicators, life cycle approach and multi-criteria to assess the overall environmental impact. They outline advantages and disadvantages of the three independent methods and set up a few environmental performance indicators to bridge the gap between LCA and Analytic Hierarchy Process (AHP). AHP was originally proposed by Saaty in 1971. It has been widely used to treat complex problems [7] [8]. Similar concepts have been proposed by other researchers. For example, while evaluating energy alternatives, Papandreou and Shang [9] calculated the life-cycle emission of SOx, $\mathrm{CO}, \mathrm{CO}_{2}, \mathrm{CH}_{4}, \mathrm{~N}_{2} \mathrm{O}$ and NOx to reflect the environmental burden and then established economic and environmental evaluation criteria for a multi-objective optimal combined with linear programming analysis. They then identify, among various renewable energies, the one which has the minimal cost and environmental impact. Roth et al. [10] applied LCA, probabilistic safety assessment (PSA) and MCA in their study. They use seventy-five indicators in environmental, economic and social aspects to evaluate eighteen energy generation technologies. The result indicates that hydropower and geothermal technology are relatively sustainable as compared to others.

Although energy is a global issue, countries are faced with different situations and problems. The purpose of the present study is to find better choices among various renewable energy development plans in Taiwan. Unlike many previous studies which consider only environmental or economic factors, the present study incorporates meaningful 3E (Energy-Economics-Environment) indicators to reflect the integrated performances of certain selected renewable energy development plans and combines LCA and MCA as well. Since wind power and photovoltaic (PV) systems are found to be more feasible as compared to other types of renewable energy in Taiwan [11], the consideration here is limited to these two types. For each of the two energy types, several development plans varying in development size and scale are included in the study for comparison purpose.

\section{Methods}

As the procedure of this study is shown in Figure 1. LCA is first employed to evaluate environmental impacts of the selected renewable energy development plans. Secondly, several $3 \mathrm{E}$ indicators are adopted and their values calculated from the results of LCA. Thirdly, the 3E indicators are used as evaluation criteria for the performances of AHP based on expert opinions. Finally, the result of AHP is used to find better choices among energy development plans.

\subsection{Life Cycle Assessment}

When performing LCA, we choose to employ the SimaPro software package for its mature development and numerous built-in data. The analytical procedure used in SimaPro follows the principles of ISO 14040 [12].

Among the various impact assessment methods provided in SimaPro, Eco-indicator $99(\mathrm{H})$ is chosen due to its complete and well-organized structure compared to others. There are in total eleven impact categories listed in 
Eco-indicator $99(\mathrm{H})$ including carcinogens, respiratory organics, respiratory inorganics, climate change, radiation, ozone layer, ecotoxicity, acidification/eutrophication, land use, minerals, and fossil fuels. Eco-indicator 99 (H) groups the above eleven impact categories into three areas namely human health, ecosystem quality and resources under the heading of damage categories as shown in Table 1. It uses normalization factors and appropriate weights of damage to remove dimensional units of different categories and standardize their related importance measures. DALY in Table 1 represents "disability adjusted life year", PAF indicates "potentially affected fraction", PDF represents "potentially disappeared fraction" and MJ indicates "mega joule". At the end, one can obtain impact points for different categories to describe their environmental influences.

\subsection{E Indicators}

Energy, economics, and environmental (3E) indicators can be used to measure the performance of renewable energy development plans in three aspects. The $3 \mathrm{E}$ indicators considered relatively important in Taiwan and used in the present study are described below.

1) Energy indicator-energy gained ratio

The energy gained ratio (EGR) is modified from the primary energy ratio [3] and defined as the ratio of energy generated to energy input. Its expression is as follows:

$$
\mathrm{EGR}=\frac{E_{\text {gen }}}{E_{\text {in }}}
$$

in which $E_{g e n}$ indicates the total energy generated for a renewable energy development plan and $E_{\text {in }}$ represents the total energy input. Both are parts of the life cycle of a development plan. Higher value of EGR reflects the use of specific renewable energy can generate more electricity out of the same amount of energy resource.

2) Economics indicator-average generation cost

The average generation cost (AGC) is the most commonly used economic indicator to assess a power system's performance. In the present study, AGC is referred to literature [13] and defined as the cost per kWh of net energy delivered by the system of an energy development plan. By using the present value, one can find

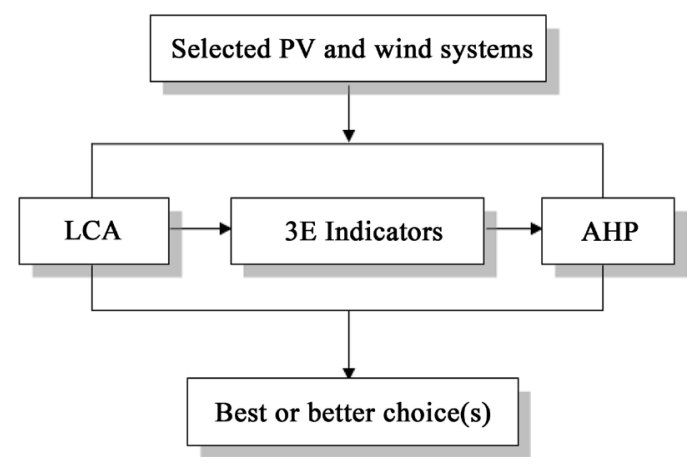

Figure 1. Procedure of the study.

Table 1. Categories in Eco-indicator $99(\mathrm{H})$.

\begin{tabular}{ccc}
\hline Impact category & Unit & Damage category \\
\hline Carcinogens & DALY & \\
Respiratory organics & DALY & \\
Respiratory inorganics & DALY & Human health \\
Climate change & DALY & \\
Radiation & DALY & \\
Ozone layer & DALY & \\
Ecotoxicity & PAF $\cdot \mathrm{m}^{2} \cdot$ year & \multirow{2}{*}{ Ecosystem quality } \\
Acidification/Eutrophication & PDF $\cdot \mathrm{m}^{2} \cdot$ year & \\
Land use & $\mathrm{PDF} \cdot \mathrm{m}^{2} \cdot$ year & Resources \\
Minerals & $\mathrm{MJ} \mathrm{surplus}$ & \\
Fossil fuels & $\mathrm{MJ} \mathrm{surplus}$ & \\
\hline
\end{tabular}


AGC through

$$
\mathrm{AGC}=\frac{C_{t}}{E_{\text {gen }}}=\frac{C_{i}+C_{m}^{\prime}}{E_{\text {gen }}}
$$

in which $C_{t}$ is the total life-cycle cost which consists of the initial investment $C_{i}$ and the maintenance cost $C_{m}^{\prime}$ presented in present value. The latter can be calculated from

$$
C_{m}^{\prime}=\sum_{j=0}^{n} \frac{C_{m}}{(1+r)^{j}}
$$

where $C_{m}$ is the nominal maintenance cost, $r$ is the fixed interest rate, $j$ indicates the operation period, and $n$ indicates the life-cycle operation period. The operation period is usually measured in years.

3) Environmental indicator I-global warming potential

Global warming is a very important environmental issue today. The rising global temperature can result in critical consequences on environment, economy as well as human health. The global warming potential (GWP) reflects the potential influence of greenhouse gases while producing per $\mathrm{kWh}$ of electricity [13]. To measure GWP, the one used in IPCC 2007 [14] is adopted in the present study. It primarily quantifies the emission of carbon dioxide equivalent versus electricity generated per unit and can be expressed as

$$
\mathrm{GWP}=\frac{G E}{E_{\text {gen }}}
$$

in which $G E$ represents the sum of greenhouse gases multiplied by the corresponding global warming factors, and $E_{\text {gen }}$ is the electricity generated. Since the carbon dioxide equivalent is frequently measured in $\mathrm{kg}\left(\mathrm{CO}_{2^{-}}\right.$ Equation), the GWP is usually measured in $\mathrm{kg}\left(\mathrm{CO}_{2}\right.$-eq) $/ \mathrm{kWh}$.

4) Environmental indicator II—and use

The land occupied by an energy generation system may affect human activities, increase pressure on the environment, and destabilize the ecosystem [13]. In countries such as Taiwan, land is rare and its use is an important issue in the evaluation of renewable energy development. In the present study, when considering wind energy, the indicator $L_{U w t}$ which represents the land use per $\mathrm{kWh}$ of single wind turbine $\left(\mathrm{m}^{2} / \mathrm{kWh}\right)$ is created and used for evaluation, and expressed as:

$$
L_{U w t}=\frac{L_{w t}}{E_{g e n}}
$$

in which $L_{w t}$ indicates the minimal usage of land of a single set of wind turbine, and $E_{\text {gen }}$ represents the lifecycle energy generated by the wind turbine. The former can be estimated from

$$
L_{w t}=\left(\frac{3 d}{2}\right)\left(\frac{5 d}{2}\right)
$$

in which $d$ is the rotor diameter of the wind turbine. For PV systems, the indicator $L_{U P V}$ which represents the land use per $\mathrm{kWh}$ of every PV system $\left(\mathrm{m}^{2} / \mathrm{kWh}\right)$ is considered and expressed as:

$$
L_{U P V}=\frac{L_{P V}}{E_{g e n}}
$$

in which $L_{P V}$ is the total land needed for setting up a PV system, and $E_{g e n}$ is the life-cycle energy generated by PV system.

\subsection{Multi-Criteria Analysis (MCA)}

$3 \mathrm{E}$ indicators can be used as criteria to determine the best or better choices among various renewable energy development plans. However, they may contradict with one another when measuring the performance of development plans. One development plan may be best from the environmental viewpoint, but worse off when considering energy. Therefore, all 3E indicators must be considered simultaneously and as a whole. To this end, one of the mature multi-criteria analysis methods, AHP, is adopted in the present study for its efficiency and good 
performance. To be compatible with terminology used in AHP for MCA, the development plans are also called alternatives in this study. The AHP used in the present study contains the following procedures.

1) Goal definition

Well defined boundary and decision goal are constructed to gather the related information of problems.

2) Decision group

Based on the complexity of problems and the domains involved, we can choose $5 \sim 15$ experts to team up a decision group in decision making.

3) Decision criteria, hierarchy structure, and alternative plans

The decision criteria are based on a few key $3 \mathrm{E}$ indicators. They are considered relatively important in Taiwan. A hierarchical structure is then constructed and several alternative energy plans are selected for further analysis.

4) Priorities of criteria

In AHP, experts are asked to determine priorities by making a series of judgments based on pair-wise comparisons of elements. By comparing the criteria, one can compute the relative priority weights of criteria at each level. An important work in AHP is to coordinate experts' judgments to obtain integrated weights of criteria. Another important work is to confirm whether the judgments of pair-wise comparisons made by experts are consistent. A consistency index (CI) and a consistency ratio (CR) [15] are used and examined in this study for this purpose.

5) Alternatives' performance evaluation

For each alternative, the performance value related to each criterion has to be estimated based on field data or available database. Calculation using Equations ((1) to (7)) or other related equations and formulas may be necessary. These performance values may also have to be normalized before a decision can be made.

6) Integrated scores of alternatives

At each level of AHP, the performance values are multiplied by their weights obtained from MCA which is carried out based on input from the decision group. They are added together for use at a higher level. The process continues until it reaches the highest level. The alternative which has the highest score indicates the best choice among alternatives.

\section{Calculations and Results: Case Study on PV Systems and Wind Turbines in Taiwan}

With regard to renewable energy at the current stage, PV systems and wind turbines are found to be more feasible in Taiwan. Therefore, a few available types of PV systems and wind turbines are considered as alternatives in the present study.

For PV systems, crystalline silicon-based PV technology dominates the renewable energy market worldwide. In particular, the single-crystalline silicon-based (sc-Si) and multi-crystalline silicon-based (mc-Si) systems are the two most popular and matured technologies [16]. Photovoltaic balance of system (BOS) components affect the power generation of a PV system. To be consistent with the current industrial status in Taiwan, the case study focuses on sc-Si and mc-Si cells with flat roof or ground-mounted power plants for the assessment of their $3 \mathrm{E}$ performances. The average solar radiation is set to be $1207.3 \mathrm{kWh} / \mathrm{m}^{2}$ to reflect the radiation condition in Taiwan [17]. The basic information of the four types of PV systems selected is shown in Table 2.

Like PV systems, wind power is another popular choice of renewable energy in the global market. In wind power market, in addition to the matured technology of onshore wind turbines, the number of offshore wind farms also increases rapidly [18]. In the present study, both onshore and offshore wind turbines are considered. The following four types of wind turbines are selected: $600 \mathrm{~kW}$ (onshore), $1500 \mathrm{~kW}$ (onshore), $2500 \mathrm{~kW}$ (onshore and offshore in $25 \mathrm{~km}$ ), and $4500 \mathrm{~kW}$ (onshore). They are available in the current market and believed to be more appropriate for use in Taiwan. Among the selected turbines, the one which has $2500 \mathrm{~kW}$-capacity is considered to be installed either onshore or offshore. To be compatible with the environmental condition in Taiwan, the wind velocity on land is set to be $6.26 \mathrm{~m} / \mathrm{sec}$ which is the average record of Chunfong wind power demonstration field in Hsinchu County. For offshore condition, the average wind velocity is set to be $9.36 \mathrm{~m} / \mathrm{sec}$, which is the situation of Jhongtun wind power demonstration field in Penghu County. The basic information of the selected five types of wind turbines and the amount of energy generated for each single wind turbine during its life-cycle is investigated and listed in Table 3. 
Table 2. Basic information of PV systems.

\begin{tabular}{|c|c|c|c|c|}
\hline & SC-Flat roof & MC-Flat roof & SC-Ground & MC-Ground \\
\hline Capacity (kWp) & 3 & 3 & 1000 & 1000 \\
\hline Tilt angle $\left(^{\circ}\right)$ & 30 & 30 & 30 & 30 \\
\hline Average solar radiation $\left(\mathrm{kWh} / \mathrm{m}^{2}\right)$ & 1207.3 & 1207.3 & 1207.3 & 1207.3 \\
\hline System lifetime (year) & 25 & 25 & 25 & 25 \\
\hline Module efficiency (\%) & 20 & 18 & 20 & 18 \\
\hline Active surface $\left(\mathrm{m}^{2}\right)$ & 15 & 16.68 & 5000 & 5560 \\
\hline Cell thickness $(\mu \mathrm{m})$ & 180 & 180 & 180 & 180 \\
\hline Inverter & Solcon $3400 \mathrm{HE}$ & Solcon $3400 \mathrm{HE}$ & SUNWAY T & SUNWAY T \\
\hline BOS total efficiency (\%) & 85 & 85 & 89.28 & 89.28 \\
\hline Life-cycle energy (kWh) & $76,765.03$ & $76,765.03$ & $26,947,170.36$ & $26,947,170.36$ \\
\hline
\end{tabular}

Table 3. Basic information of wind turbines.

\begin{tabular}{|c|c|c|c|c|c|}
\hline & \multirow{2}{*}{ Vestas-V44 } & \multirow{2}{*}{ Enercon-E66 } & \multicolumn{2}{|c|}{ Nordex-N80 } & \multirow{2}{*}{$\begin{array}{c}\text { Enercon-E112 } \\
\text { On-shore }\end{array}$} \\
\hline & & & On-shore & Off-shore, 25 km & \\
\hline Capacity (kW) & 600 & 1500 & 2500 & 2500 & 4500 \\
\hline Rotor diameter (m) & 44 & 66 & 80 & 80 & 113 \\
\hline Swept area $\left(\mathrm{m}^{2}\right)$ & 1521 & 3421 & 5026 & 5026 & 10,220 \\
\hline Height of tower (m) & 37 & 67 & 60 & 60 & 124 \\
\hline Tower & Tubular & Tubular & Tubular & Tubular & Tubular \\
\hline Wind velocity (m/sec) & 6.26 & 6.26 & 6.26 & 9.36 & 6.26 \\
\hline Average air density $\left(\mathrm{kg} / \mathrm{m}^{3}\right)$ & 1.293 & 1.293 & 1.293 & 1.293 & 1.293 \\
\hline System lifetime (year) & 20 & 20 & 20 & 20 & 20 \\
\hline Full load hours (h/y) & 2500 & 2500 & 3000 & 4000 & 4000 \\
\hline Transforming loss (\%) & 1 & 1 & 1 & 3 & 1 \\
\hline Life-cycle energy (kWh) & $11,940,594.27$ & $26,856,524.01$ & $47,347,871.26$ & $206,766,549.78$ & $128,371,201.56$ \\
\hline
\end{tabular}

\subsection{Data Collection and LCA}

To calculate the energy input and environmental impacts for the selected renewable energy development plans for use in LCA, principles documented in ISO 14,040 are followed. First, the four items are defined and/or stated.

1) Goal

This study is to use LCA tools to calculate the life-cycle inputs, outputs of the selected PV systems and wind turbines, and turn the results into $3 \mathrm{E}$ indicators.

2) Functional unit

The functional unit referred to in this study is every kWh of electricity delivered to the power grid at low voltage.

3) Boundary

Life-cycle phases such as manufacturing of components, transportation and operation are considered in the study as those shown in Figure 2.

4) Assumptions

The following assumptions are made in this study:

a) The lifetime of the PV system is 25 years, and the lifetime of the wind turbine system is 20 years;

b) The transportation of raw material is not taken into account;

c) The distance of land transportation and maintenance is $100 \mathrm{~km}$ which is the approximate distance travelling across three counties in Taiwan. The ocean shipment distance is $26,500 \mathrm{~km}$ which is approximately the distance 


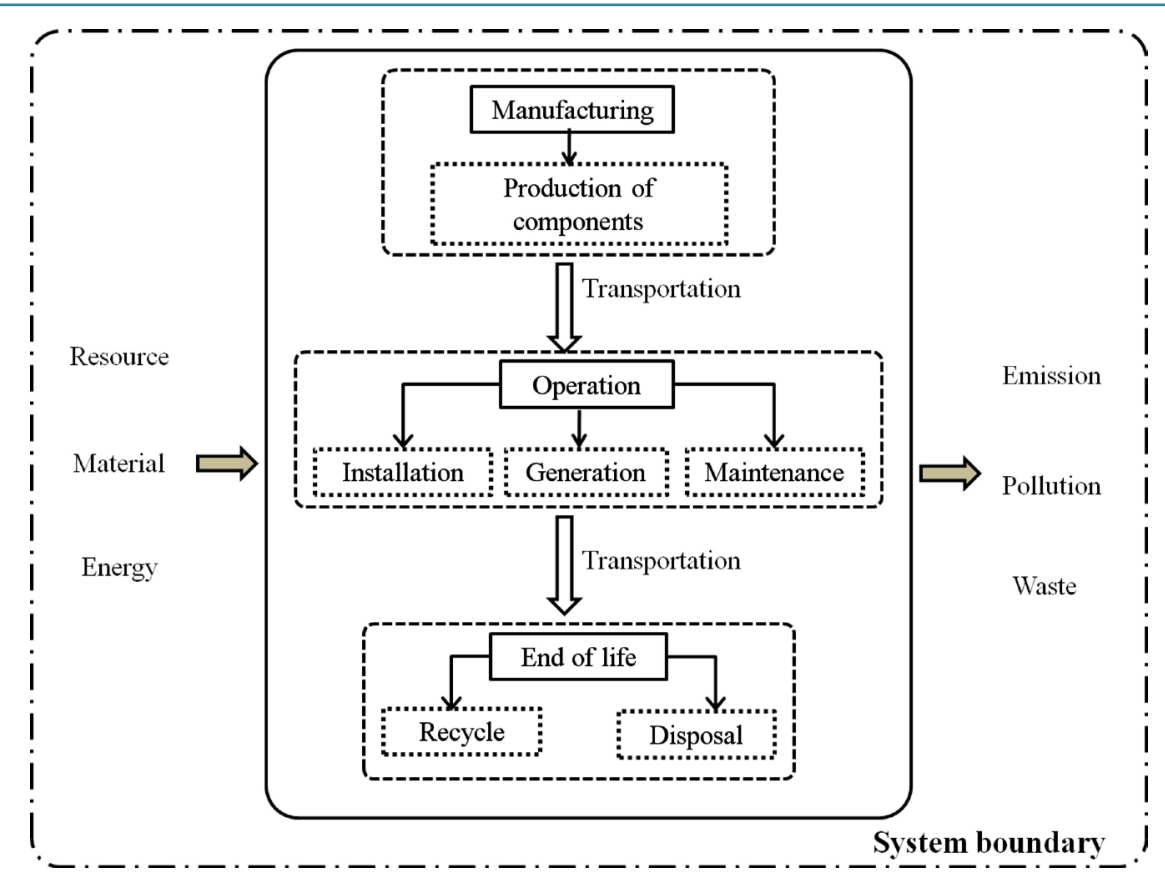

Figure 2. System boundary of LCA.

from Denmark to Taiwan when considering import of wind-turbine components;

d) The conveyance of land transportation requires 40-ton trucks. For ocean shipment, container ships are used;

e) SimaPro software package is used for LCA, in which a European database [19] is used for references when local data are not available;

f) Ninety percents of metals including aluminum, iron and steel are recycled. The rest of used components and building materials are sent to landfill;

g) One blade and 0.15 nacelles are replaced with new ones for each wind turbine in its lifetime. For each PV system, one inverter is replaced with a new one in its lifetime.

After determining the goal, the functional unit, the boundary, and making appropriate assumptions, LCA is performed. To begin with, a detailed life-cycle inventory of various subjects is established within the boundary. For data which are not available in Taiwan, those documented in reports of Environmental and Ecological Life Cycle Inventories for Present and Future Power Systems in Europe (ECLIPSE) and Ecoinvent database v2.0 [16] [18] [19] are adopted. The data in the inventory list are then imported to SimaPro in order to find different kinds of environmental impact.

Figure 3 summarizes the LCA results of the nine selected renewable energy development plans. In the figure, the damage is divided into three major categories based on the classification of (Table 1), each quantified by impact points per kWh of energy generated. It is found that PV systems and wind turbines result in more damage to human health and resources than to ecosystem quality. For the eleven impact categories as those shown in Table 1, the LCA results are shown in Figure 4. It is found that respiratory inorganics, minerals and fossil fuel cause more impact on the environment than others. It should be noted that impact points in the above two figures are normalized with respect to the life-cycle energy generated for each alternative plan to make the comparison more meaningful.

The results of Figure 3 and Figure 4 also show that wind turbines have lower impact points than those of PV systems that make them better choices in Taiwan. Among the studied wind turbines, the 2500-kW offshore design causes the least environmental damage and impact per kWh of energy generated. It is the best choice among the nine studied alternatives when only the environmental LCA result is considered.

\subsection{E Performance Analysis}

In the present study, in considering local situation and available data, the energy gained ratio (EGR), average generation cost (AGC), global warming potential (GWP) and land use as those introduced in Section 2 are se- 
lected as the four $3 \mathrm{E}$ indicators. Based on data tabulated in Table 2 and Table 3 and calculation from Equations ((1) to (7)), the results are summarized in Table 4. With regard to EGR, it indicates EGR of wind turbines is generally higher than that of PV systems. It reflects that wind power is a better choice than PV system in Taiwan in this aspect. It is also found once again that the $2500-\mathrm{kW}$ offshore turbine has the highest EGR among all selected alternatives. Considering Taiwan is an island country, it is of no surprise that an offshore turbine system has higher energy benefit than that of an equivalent onshore one.

With regard to AGC, it is obtained by dividing the life cycle cost by total life cycle energy generated for each

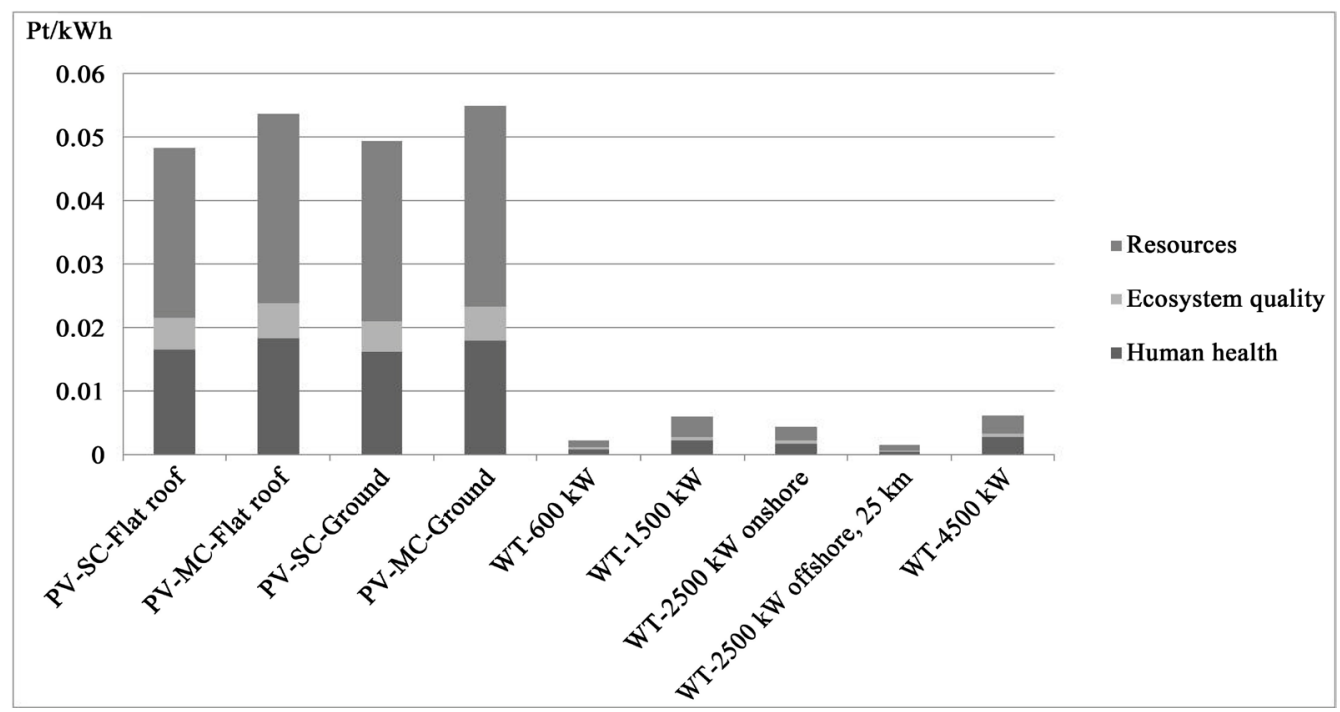

Figure 3. Damage in three categories.

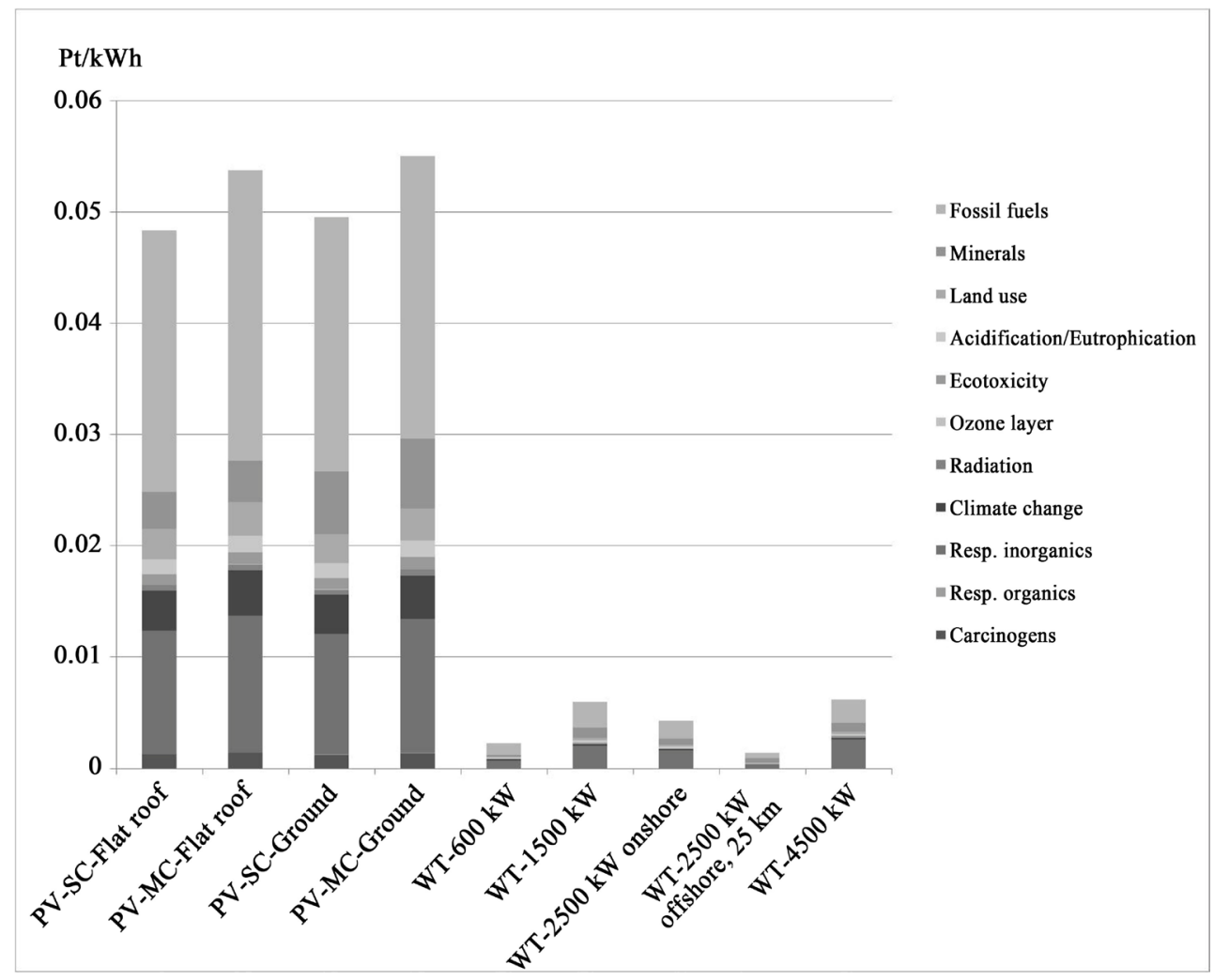

Figure 4. Impact in eleven categories. 
alternative. The life-cycle cost considered in the present study consists of the initial investment and the maintenance cost. The initial investment is the expense for the construction of a renewable energy generation system, and the maintenance cost is the need for its normal operation. By using Equations ((2) and (3)) as well as data adopted from International Energy Agency [20], Solarbuzz Limited Liability Company [21] and Raugei and Frankl [22], the average generation costs for all alternatives of this study are calculated and summarized in Table 4, with other indices also shown therein and some will be explained in detail later on. It indicates that AGC of PV systems are much higher than those of wind turbines and wind turbines show their economic dominances over PV systems. When comparison is made among the five wind turbines, it is observed that large-capacity turbines usually have more economic advantages over small-capacity ones. For same capacity, an offshore design has more economic advantage than that of an onshore system.

To evaluate GWP, the result of LCA is used. In the calculation, every kind of emission related to global warming of renewable energies is multiplied by a corresponding weight suggested by SimaPro resulting in the emission of carbon dioxide equivalent. They are then added together to reflect the summarized greenhouse effect. GWP is calculated by dividing the value by the life-cycle energy generated based on Equation (4). Again, the summarized result of GWP for all alternatives is shown in Table 4. It is found that wind turbines are more environmental friendly than PV systems. Among the studied wind turbines, in the same capacity, offshore types result in less greenhouse effect than onshore designs. For PV systems, ground plants and multi-crystalline silicon types cause more environmental burdens.

With regard to land use, owing to limited land in Taiwan, it is believed that land use should be a key performance indicator. Values of this indicator for all alternatives are calculated based on Equations ((5) to (7)) and summarized in Table 4. It is found that land use of PV systems is generally less than that of any wind turbine. For wind turbines, offshore types are better than onshore ones. Among selected onshore designs, land use usually decreases with increasing installation capacity.

In addition to providing direct decision-making support, the above $3 \mathrm{E}$ indicators can also be used in conjunction with opinions from experts for further analysis based on AHP.

\subsection{Analysis Integrated with AHP}

The use of AHP is to find, among the nine renewable energy alternatives, the one that has the most advantage or those who have more advantage as compared to others. To simplify the decision-making process, the 3E indicators mentioned previously are selected as measurement tools in constructing the hierarchical structure. They are also used for building decision criteria needed in AHP. Hereafter, the three indicators energy, economics and environment are also called 'dimensions', and EGA, AGC, GWP and land use are called 'criteria' for simplicity sake.

In the present study, the opinions and judgments come from a decision-making group made up of seven professors of National Taiwan University who have been engaging in energy related researches. Some of them also serve as consultants in related government agencies. These experts determine priority weights of different criteria from filling out questionnaires.

Based on experts' opinions, the weights of $3 \mathrm{E}$ dimensions and criteria are calculated as those shown in Table 5. Owing to limited space, the detail of the analysis is not included in this paper but can be found in Chang [11]. From the AHP result of Table 5, it is observed that, among the tabulated three indicators (dimensions), environment is the first priority and economics ranks second. With regard to the two tabulated environmental indicators (criteria), global warming potential has higher priority than land use.

Data in Table 6 are obtained from combining Table 4 and Table 5 and represent final results with respect to all nine alternatives. The result indicates that $2500-\mathrm{kW}$ wind turbine with an offshore design receives the highest score of 0.89 and is therefore the best choice among all alternatives. The second best choice is the $4500-\mathrm{kW}$ onshore wind turbine. The result also indicates that wind turbines in general have more integrated advantages than PV systems. It can also be seen from Table 6 that, for onshore wind turbines, with increasing capacity from $1500 \mathrm{~kW}$ to $4500 \mathrm{~kW}$, the integrated $3 \mathrm{E}$ advantage also increases. Meanwhile, for same capacity, offshore designs turn out to be better than onshore systems. These observations agree mostly with results from previous simpler analyses and confirm the rationale of the present study.

\section{Conclusions}

In this study, LCA, 3E indicators and AHP are integrated to offer a systematic approach for decision makers to 
Table 4. Result of 3E indicators.

\begin{tabular}{|c|c|c|c|c|c|c|c|c|c|}
\hline \multirow[t]{3}{*}{ 3E indicator } & \multicolumn{9}{|c|}{ Alternative } \\
\hline & \multicolumn{2}{|c|}{ PV-Flat roof } & \multicolumn{2}{|c|}{ PV-Ground } & \multirow{2}{*}{$\begin{array}{l}\text { WT-600 } \\
\text { kW }\end{array}$} & \multirow{2}{*}{$\begin{array}{c}\text { WT-1500 } \\
\text { kW }\end{array}$} & \multicolumn{2}{|c|}{ WT-2500 kW } & \multirow[t]{2}{*}{ WT-4500 kh } \\
\hline & SC & MC & SC & MC & & & On-shore & Off-shore, 25 km & \\
\hline Energy gained ratio & 0.17 & 0.16 & 0.18 & 0.16 & 9.90 & 5.05 & 7.03 & 17.45 & 6.56 \\
\hline $\begin{array}{l}\text { Average generation } \\
\text { cost (NTD/kWh) }\end{array}$ & 6.92 & 6.64 & 5.55 & 5.28 & 2.28 & 2.54 & 2.40 & 1.32 & 1.59 \\
\hline $\begin{array}{l}\text { Global warming potential } \\
\left(\mathrm{kg}\left(\mathrm{CO}_{2} \text {-eq. }\right) / \mathrm{kWh}\right)\end{array}$ & 0.94 & 1.05 & 0.91 & 1.01 & 0.02 & 0.04 & 0.03 & 0.01 & 0.04 \\
\hline Land use (m²/kWh) & $1.95 \mathrm{E}-0$ & $2.17 \mathrm{E}-04$ & $1.86 \mathrm{E}-04$ & $2.06 \mathrm{E}-04$ & $6.08 \mathrm{E}-04$ & $6.08 \mathrm{E}-04$ & $5.07 \mathrm{E}-04$ & $1.16 \mathrm{E}-04$ & $3.73 \mathrm{E}-04$ \\
\hline
\end{tabular}

Table 5. Weights of dimensions and criteria.

\begin{tabular}{ccccc}
\hline 3E dimension & Weight of dimension & 3E criterion & Weight of criterion & Integrated weight \\
\hline Energy & 0.154 & Energy gained ratio & 1 & 0.154 \\
Economics & 0.354 & Average generation cost & 1 & 0.354 \\
& \multirow{2}{*}{0.492} & Global warming potential & 0.590 & 0.290 \\
Environment & & Land use & 0.410 & 0.202 \\
\hline
\end{tabular}

Table 6. Normalized performances of alternatives and final scores.

\begin{tabular}{|c|c|c|c|c|c|c|c|c|c|c|}
\hline \multirow[t]{3}{*}{ Criterion } & \multirow[t]{3}{*}{$\begin{array}{l}\text { Integrated } \\
\text { weight }\end{array}$} & \multicolumn{9}{|c|}{ Alternative } \\
\hline & & \multicolumn{2}{|c|}{ PV-Flat roof } & \multicolumn{2}{|c|}{ PV-Ground } & \multirow[t]{2}{*}{$\begin{array}{l}\text { WT-600 } \\
\text { kW }\end{array}$} & \multirow[t]{2}{*}{$\begin{array}{l}\text { WT-1500 } \\
\text { kW }\end{array}$} & \multicolumn{2}{|c|}{ WT-2500 kW } & \multirow{2}{*}{$\begin{array}{c}\text { WT-4500 kW } \\
\text { On-shore }\end{array}$} \\
\hline & & SC & MC & SC & MC & & & On-shore & Off-shore, 25 km & \\
\hline Energy gained ratio & 0.154 & 0.01 & 0.01 & 0.01 & 0.01 & 0.57 & 0.29 & 0.40 & 1.00 & 0.38 \\
\hline $\begin{array}{l}\text { Average generation } \\
\text { cost (NTD/kWh) }\end{array}$ & 0.354 & 0.00 & 0.04 & 0.20 & 0.24 & 0.67 & 0.63 & 0.65 & 0.81 & 0.77 \\
\hline $\begin{array}{l}\text { Global warming potential } \\
\left(\mathrm{kg}\left(\mathrm{CO}_{2} \text {-eq. }\right) / \mathrm{kWh}\right)\end{array}$ & 0.290 & 0.10 & 0.00 & 0.13 & 0.04 & 0.98 & 0.96 & 0.97 & 0.99 & 0.96 \\
\hline Land use $\left(\mathrm{m}^{2} / \mathrm{kWh}\right)$ & 0.202 & 0.68 & 0.64 & 0.69 & 0.66 & 0.00 & 0.00 & 0.17 & 0.81 & 0.39 \\
\hline Score & & 0.17 & 0.15 & 0.25 & 0.23 & 0.61 & 0.55 & 0.61 & 0.89 & 0.69 \\
\hline
\end{tabular}

select appropriate renewable energy generation systems and energy development plans. From the results of LCA, it is concluded that generation of respiratory inorganics, minerals and fossil fuel consumption is the three major environmental impacts when developing PV and wind systems in Taiwan. To reduce these impacts, manufacturers may consider decreasing the amount of related inputs or using substitutive materials engaged in LCA. The results also conclude that wind turbines cause less environmental burden than that of PV systems. In particular, the $2500-\mathrm{kW}$ wind turbine system with offshore design is found to be the most environmental-friendly one. Economic factors are also taken into consideration to complete the $3 \mathrm{E}$ analysis. From the result of $3 \mathrm{E}$ analysis, it is concluded that, referring to EGR, AGC and GWP, wind turbines have more advantages than PV systems. However, with regard to land use, PV systems are more advantageous than wind turbines. For same capacity, an offshore turbine system has better 3E performance than an onshore system. It is worth mentioning that the generation cost per $\mathrm{kWh}$ as shown in Table 4 is under $2 \mathrm{NT}$ dollars if the 2500-kW offshore wind turbine or 4500-kW onshore system is considered. It shows a remarkable economic potential since the current electricity charge per kWh in Taiwan is generally over 2 NT dollars. The cost of an onshore wind turbine system is found to decrease with increasing capacity. It suggests that wind turbines with higher capacities are better selections, which agree with world trend. From the result of AHP, it is concluded that the 2500-kW offshore wind turbine system is still the best choice among all alternatives. The second best choice is the $4500-\mathrm{kW}$ onshore system. The outcome confirms that offshore designs and large-capacity wind turbines hold considerable advantages in the renewable energy development plans available in Taiwan. 
The systematic approach proposed in the present study has proven its efficiency for the case study in Taiwan and should be able to be applied to other countries under similar conditions.

\section{References}

[1] Udo de Haes, H.A. and Heijungs, R. (2007) Life-Cycle Assessment for Energy Analysis and Management. Applied Energy, 84, 817-827. http://dx.doi.org/10.1016/j.apenergy.2007.01.012

[2] Martinez, E., Sanz, F., Pellegrini, Jimenez, E. and Blanco, J. (2009) Life Cycle Assessment of a Multi-Megawatt Wind Turbine. Renewable Energy, 34, 667-673. http://dx.doi.org/10.1016/j.renene.2008.05.020

[3] Wang, J.J., Jing, Y.Y., Zhang, C.F. and Zhao, J.H. (2009) Review on Multi-Criteria Decision Analysis Aid in Sustainable Energy Decision-Making. Renewable and Sustainable Energy Reviews, 13, 2263-2278. http://dx.doi.org/10.1016/j.rser.2009.06.021

[4] Chang, P.L., Hsu, C.W. and Lin, C.Y. (2012) Assessment of Hydrogen Fuel Cell Applications Using Fuzzy Multiple-Criteria Decision Making Method. Applied Energy, 100, 93-99. http://dx.doi.org/10.1016/j.apenergy.2012.03.051

[5] Cavallaro, F. (2009) Multi-Criteria Decision Aid to Assess Concentrated Solar Thermal Technologies. Renewable and Sustainable Energy Reviews, 34, 1678-1685. http://dx.doi.org/10.1016/j.renene.2008.12.034

[6] Hermann, B.G., Kroeze, C. and Jawjit, W. (2007) Assessing Environmental Performance by Combining Life Cycle Assessment, Multi-Criteria Analysis and Environmental Performance Indicators. Journal of Cleaner Production, 15, 1787-1796. http://dx.doi.org/10.1016/j.jclepro.2006.04.004

[7] Teng, J.Y. (2005) Project Evaluation: Methods and Applications. Operations Planning and Management Center, Taipei.

[8] Granat, J. and Makowski, M. (2006) Multi-Criteria Methodology for the NEEDS Project. New Energy Externalities Developments for Sustainability (NEEDS) Integrated Project.

[9] Papandreous, V. and Shang, Z.G. (2008) A Multi-Criteria Optimization Approach for the Design of Sustainable Utility Systems. Computer \&Chemical Engineering, 32, 1589-1602. http://dx.doi.org/10.1016/j.compchemeng.2007.08.006

[10] Roth, S., Hirschberg, S., Bauer, C., Burgherr, P., Dones, R., Heck, T. and Schenler, W. (2009) Sustainability of Electricity Supply Technology Portfolio. Annals of Nuclear Energy, 36, 409-416. http://dx.doi.org/10.1016/j.anucene.2008.11.029

[11] Chang, Y.J. (2010) Application of Life Cycle Assessment and Multi-Criteria Decision Making to the Selection of Renewable Energy. Master's Study, Graduate Institute of Industrial Engineering, National Taiwan University, Taipei.

[12] ISO (1998) ISO 14040 Life Cycle Assessment-Principles and Framework. International Organization for Standardization, Geneva.

[13] Hirschberg, S., Bauer, C., Burgherr, P., Dones, R., Schenler, W., Bachmann, T. and Carrera, D.G. (2007) Environmental, Economic and Social Criteria and Indicators for Sustainability Assessment of Energy Technologies. New Energy Externalities Developments for Sustainability (NEEDS) Integrated Project.

[14] Metz, B., Davidson, O.R., Bosch, P.R., Dave, R. and Meyer, L.A. (2007) Mitigation of Climate Change. The Fourth Assessment Report of the Intergovernmental Panel on Climate Change. http://www.ipcc.ch/index.htm

[15] Saaty, T.L. (1980) The Analytic Hierarchy Process, Planning, Priority Setting, Resource Allocation. McGraw-Hill, New York.

[16] Frankl, P., Corrado, A. and Lombardelli, S. (2004) Photovoltaic Systems Final Report. Environmental and Ecological Life Cycle Inventories for Present and Future Power Systems in Europe (ECLIPSE).

[17] Ou, W.S., Ho, M.C., Chen, J.L., Chen, J.F. and Lo, S.C. (2008) The Study on the Typical Radiation for Solar Architecture Design of Taiwan. Journal of Architecture, 64, 103-118.

[18] Chataignere, A. and Leboulch, D. (2003) Wind Turbines Systems Final Report. Environmental and Ecological Life Cycle Inventories for Present and Future Power Systems in Europe (ECLIPSE).

[19] Ecoinvent Data v2.0. (2010) Swiss Centre for Life Cycle Inventories. http://www.ecoinvent.org

[20] International Energy Agency (2008) Renewable Energy Essentials: Wind. http://www.iea.org

[21] Solarbuzz Limited Liability Company (2010) http://www.solarbuzz.com/index.asp.

[22] Raugei, M. and Frankl, P. (2009) Life Cycle Impacts and Costs of Photovoltaic Systems: Current State of the Art and Future Outlooks. Energy, 34, 392-399. http://dx.doi.org/10.1016/j.energy.2009.01.001 